\title{
Um trabalho a troco de nada? A ação de uma comunidade de hackers à luz da teoria da dádiva
}

\section{Resumo}

Mais do que apontar possíveis respostas para um "enigma" contemporâneo, este artigo discute as especificidades da dinâmica de trabalho dos hackers, no processo de produção não-contratual e colaborativo, presente na comunidade on-line de desenvolvimento de softwares do Projeto GNOME (GNU Network Object Model Environment). A partir de uma imersão netnográfica de mais de um ano, analisou-se a organização do trabalho que dá vida ao processo de produção empreendido por mais de 300 hackers e colaboradores de todos os cinco continentes do planeta. Mais especificamente, buscou-se compreender a natureza do trabalho adotado pelos hackers ao longo do desenvolvimento e distribuição de softwares nessa comunidade online de abrangência internacional. Como resultado, constatou-se a presença no Projeto GNOME de um tipo de engajamento não-contratual, associado a uma forma de trabalho e circulação de bens que se difere completamente de organizações ligadas à esfera do mercado ou do Estado, mas que consegue, por meio da internet, viabilizar um processo internacional de desenvolvimento de software de alta complexidade. Em outras palavras, foi possível verificar por meio da dinâmica social empreendida no seio dessa comunidade online, a emergência, nos liames digitais da internet, de uma nova expressão da dádiva moderna: um sistema de dádiva mediada por computador, tanto na essência como no modo de funcionamento e organização do trabalho.

\footnotetext{
Universidade Federal da Bahia (Brasil)

** Universidade Federal da Bahia (Brasil)
} 
Palavras-chave: Cultura hacker. Trabalho voluntário. Dádiva. Projeto GNOME. Utilitarismo.

\title{
A work for nothing? The work of a community of hackers in the light of "The Gift" theory
}

\begin{abstract}
Rather than pointing out possible answers for a contemporary "puzzle", this article discusses the specificities of hackers' work dynamics in the case of the noncontractual and collaborative production in the online community of software development named Project GNOME (GNU Network Object Model Environment). By means of a "netnographic" immersion developed for over a year, we analyzed the organization of work that enables the production process undertaken by over 300 hackers and contributors from the five continents of the globe. We sought particularly to understand the nature of the work adopted by hackers throughout the development and distribution of software in this international online community. The findings pointed to the existence of a kind of non-contractual engagement in the GNOME project, which is associated with a mode of labor and exchange of goods that is completely different from that of the organizations either from the Market or the State, but that gets, through the internet, to enable an international process for the development of highly complex software. In other words, we could identify, in the social dynamics undertaken within this online community, the emergence of a new expression of the gift: a system of computer-mediated giving, both in its essence and in the way of operation and work organization.
\end{abstract}

Keywords: Hacker culture. Volunteer work. Gift. GNOME Project. Utilitarianism. 


\section{Introdução}

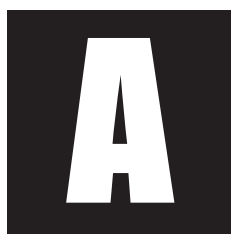

o longo das últimas décadas, a sociedade contemporânea passou a ser caracterizada como a "sociedade em rede" (Levy, 1999; Castells, 2005; Benkler, 2006). Nesta, os liames digitais da internet se afirmam como a base "tecnosocial" para a constituição de agrupamentos e organizações que impactam diretamente na dinâmica humana do mundo contemporâneo. No entanto, dentro desse contexto singular de transformações, a teoria do homo oeconomicus todavia se apresenta como paradigma dominante para entendimento da dinâmica social presente nas relações humanas contemporâneas. São poucos, até agora, os estudos que procuram analisar as características e a natureza desse novo contexto digital (de relações mediadas por dispositivos móveis como computadores, tablets e celulares) para além de um entendimento que tem como base as noções de uma racionalidade utilitária ou do simples interesse econômico. A compreensão de grande parte dos fenômenos sociais e organizacionais ainda se faz, nas ciências humanas, exclusivamente a partir desse paradigma do utilitarismo, o qual encara o comportamento e as escolhas de indivíduos e grupos como algo não-paradoxal e linear, restringindo a conduta humana a parâmetros exclusivamente racionais, numa perspectiva individualista.

Por conta disso, enigmas e questões que surgem no cotidiano dessa nova realidade "tecnosocial" ainda mantêm respostas (ou justificativas), no mínimo, reducionistas. Por exemplo, ao questionar quem pode se permitir fazer um trabalho profissional a troco de nada? numa Carta Aberta aos Hobbistas escrita em 1976 (um ano depois da fundação da então Micro-Soft), Bill Gates tenta encontrar uma resposta para seu novo modelo de negócio, por acreditar ser técnica e economicamente inviável a produção e o compartilhamento gratuitos de bons produtos tecnológicos. Quatro décadas 
depois, mais especificamente em outubro de 2006, reducionismo semeIhante ocorreu em entrevista realizada pelo apresentador Jô Soares, em um programa de televisão de audiência nacional, no Brasil. Ao ser informado por um professor universitário que colabora com algumas comunidades de produção e compartilhamento livre de software, sobre um possível engajamento voluntário de hackers, Jô Soares ressalta que, na visão dele, por trás do fato do que é dado (software) de graça há uma intenção de ser vendido. (...) ou é um pessoal que é tudo monge Franciscano?

Dentro desse contexto, para evitar nos limitarmos a uma única forma de compreensão e, com isso, restringir a análise sobre essa singular realidade (social), parece-nos imperativo entendê-la com um olhar mais científico e aprofundado, [...] pois a verdadeira questão não é ser contra ou a favor, mas sim reconhecer as mudanças qualitativas na ecologia dos signos, no ambiente inédito que resulta da extensão das novas redes de comunicação para a vida social e cultural (Lévy, 1999, p.12). Partindo dessa perspectiva, este trabalho se apoia em uma imersão netnográfica que buscou analisar a natureza do compartilhamento de tecnologia e a dinâmica social dos hackers, presentes nas comunidades online ${ }^{1}$ de desenvolvimento de software livre ${ }^{2}$ - em particular, na comunidade relativa ao Projeto GNU Network Object Model Environment, mais conhecido e difundido pela sigla GNOME.

Esse processo de imersão supôs inicialmente que a dinâmica de trabalho adotada pelos hackers estaria, de forma geral, fundada numa es-

\footnotetext{
${ }^{1}$ Neste trabalho, são consideradas como "comunidades virtuais" ou "comunidades online" os agrupamentos sociais que se manifestam na Internet em torno de um objetivo comum, onde o processo de comunicação é essencialmente mediado por computadores.

${ }^{2}$ De forma resumida, segundo Stallman (2002), pode-se dizer que software livre é todo programa de computador que, por meio da licença de uso, garante legalmente ao usuário o direito de: utilizar o software para qualquer fim; estudar seu código-fonte; modificar seu códigofonte; e, por fim, redistribuir cópias do software para qualquer finalidade de uso.
} 
pécie de engajamento eminentemente voluntário e não-contratual. Este trabalho voluntário, segundo tal pressuposto, não estaria sendo empreendido conforme princípios instrumentais e individualistas, mas sim sob princípios de liberdade e obrigação intimamente imbricados, por meio dos quais se realiza um objetivo comum: o desenvolvimento e a distribuição de um sistema computacional livre. Dito de outra maneira, ao se investigar a dinâmica de trabalho do projeto GNOME, partiu-se do princípio de que o trabalho hacker, nesta organização, poderia ser entendido por meio de uma teoria pluridimensional e paradoxal da ação humana - denominada de teoria antropológica da Dádiva.

Assim, visando compreender a natureza do engajamento adotado pelos hackers ao longo do processo de desenvolvimento e distribuição de software mediado pela internet, esse texto se estrutura em três grandes momentos. No primeiro, apresenta-se o método de investigação que viabilizou a pesquisa. Em seguida, são apresentados elementos de contextualização necessários ao entendimento da problemática aqui analisada, perpassando tanto o nível conceitual quanto empírico. Nesse sentido, discute-se a temática do hackerismo e apresenta-se o modelo "bazar" de produção colaborativa (por meio da descrição da comunidade GNOME), para, então, sugerir-se uma síntese introdutória da teoria da dádiva, cujo intuito é justamente a proposição de uma grade analítica para compreensão desse fenômeno. Finalmente, num terceiro momento, de posse dessa grade analítica e da contextualização empírica esboçada, são analisadas as características e natureza desse engajamento livre e paradoxal adotado pelos hackers, ao longo do processo de desenvolvimento tecnológico entre pares. À guisa de conclusão, são feitas algumas inferências oriundas dos resultados científicos abordados, além de apontar novas questões a serem pesquisadas. 


\section{Método de investigação}

A opção por estudar a comunidade do projeto GNOME baseou-se em critérios ligados à realidade de uma organização complexa. Assim, entre os mais de 140.000 projetos de software registrados em apenas um dos repositórios de código aberto da internet pesquisados, o Projeto GNOME foi escolhido por adotar três características em sua comunidade: o perfil dos membros ser caracterizado por pessoas de diversas faixas etárias, diferentes competências e formas de vínculo com a organização e distintas nacionalidades; existir um fluxo constante de atividades entre o grupo ao longo do processo de produção do software; e, por fim, a estrutura social em que o trabalho está dividido (hierarquia, relações de poder, subgrupos) ser bem definida.

Escolhidos o projeto e sua respectiva comunidade online, o trabaTho de coleta de dados em campo foi realizado por meio de imersão ${ }^{3}$ netnográfica dentro do ambiente digital da comunidade online analisada. Mais especificamente, esse procedimento ocorreu de duas formas. Em primeiro lugar, por meio do uso cotidiano (imersão como usuário) do software que constitui o ambiente de desktop GNOME, através de computador pessoal (PC), fazendo uso dos aplicativos que o compõem (editor de texto, editor de imagens, banco de dados, navegador de Internet, gestor de janelas e navegação, etc.), para realização de todos os procedimentos relativos a essa pesquisa. Num segundo momento, essa observação ocorreu por meio da participação direta no processo de produção do software, como membro voluntário do Projeto de Tradução

\footnotetext{
${ }^{3}$ Para uma melhor compreensão das especificidades do método netnográfico que norteou a realização deste estudo acadêmico, ver a dissertação intitulada Os Argonautas da Internet: uma análise netnográfica sobre a comunidade on-line de software livre do projeto GNOME à luz da teoria da Dádiva que se encontra disponível no link: https://repositorio.ufba.br/ri/handle/ri/8238
} 
do GNOME para o Português Brasileiro (Gnome-I10n-BR) e da lista de correio eletrônico denominada de GNOME para brasileiros. Dessa forma, apesar de não ter formação técnica em desenvolvimento de software, ao longo desse processo de pesquisa participante (de dezembro de 2005 a fevereiro de 2007), foi possível realizar uma interação direta no processo de tradução dos aplicativos que compõem o sistema GNOME para o idioma português-brasileiro, como também ajudar na discussão e elaboração de conteúdo para o site dessa comunidade local.

Para reforçar esse processo de imersão participante, foram realizadas 12 entrevistas semi-estruturadas com membros de diferentes países que participam de forma atuante no Projeto Internacional, assim como uma catalogação do perfil de 297 membros da comunidade que estavam registrados no site da Fundação GNOME, no período entre fevereiro e novembro de 2006. Para compor essa catalogação que possibilitou a compressão da identidade desses hackers, foram coletados dados em Blogs, sites, jornais eletrônicos, listas e fóruns web de discussões que foram postados desde o surgimento da comunidade GNOME. Por fim, após a conclusão das entrevistas e da catalogação, todas as impressões de campo, dados e informações coletadas foram sistematizadas e, posteriormente, confrontadas com os pressupostos teóricos que serviram de referência à pesquisa netnográfica.

\section{Sim, os hackers e não "crackers"!}

Todavia, antes de adentrarmos a análise do caso propriamente, fazse necessário esclarecer certo mal-entendido sobre o termo e a práxis social dos hackers. Afinal, o termo hacker não está associado a indivíduos irresponsáveis que visam penetrar em sistemas computacionais de forma ilícita - como é normalmente propagado pela mídia de massa tradicional. O tipo de indivíduo que viola sistemas de segurança e quebra códigos 
computacionais é denominado, especificamente, de "cracker" e, em geral, é repudiado pelos membros das comunidades internacionais de software livre, como a do GNOME.

De forma contrária a uma visão pré-concebida, este estudo considera que a práxis dos hackers fundamenta uma cultura que diz respeito ao conjunto de valores e crenças que emergiu das redes de programadores de computador que interagiam on-line em torno de sua colaboração em projetos autonomamente definidos de programação criativa (Castells, 2003, p.38). Assim, essa cultura desempenha um papel central ao longo da história de desenvolvimento dos principais símbolos tecnológicos da atual sociedade em rede (como o PC - Personal Computer, a Internet e softwares como o sistema operacional GNU/Linux) até os dias atuais. Isso porque, é esta cultura hacker que dá sustentação ao ambiente fomentador de inovações tecnológicas significativas mediante a cooperação e comunicação online, como também acaba permitindo a conexão entre o conhecimento originado em universidades e centros de pesquisas com os sub-produtos empresariais que difundem as tecnologias da informação no "mundo dos átomos" - isto é, na materialidade da sociedade contemporânea.

\section{O modelo "Bazar" de produção entre Hackers}

Partindo dessa distinção, é importante frisar que o processo de desenvolvimento de softwares em comunidades online como essa do projeto GNOME é singular em relação a um aspecto pragmático do modo de vida hacker. Enquanto

a última revolução industrial marcou a transição para uma sociedade que contava com os resultados científicos; os hackers chamam a atenção para o fato de que, na Era da Informação, mais importante que os resultados científicos é o modelo de produção entre pares, que permite obtenção desses resultados (Himanem, 2001, p.73). 
Afinal, quem pensaria, mesmo há cinco anos, que um sistema operacional de classe mundial poderia surgir como que por mágica pelo tempo livre de milhares de colaboradores espalhados por todo o planeta, conectados somente pelos tênues cordões da Internet? (Raymond, 2004, p.01).

Segundo o hacker Eric Raymond (2004), tal especulação certamente não partiria dele, pois - assim como a quase totalidade dos programadores do início da década de 1990 - ele defendia a tese de que softwares de alta complexidade, como um kernel ou um ambiente desktop, necessitavam ser desenvolvidos dentro de um "modelo catedral". Dito de outra maneira, esses sistemas computacionais, segundo o padrão de desenvolvimento anterior ao surgimento do Linux, deveriam ser elaborados de forma centralizada e isolada, por um pequeno grupo de desenvolvedores especialistas que só disponibilizariam o resultado de seu trabalho quando percebessem que uma primeira versão de determinado software estivesse significativamente pronta - assim, como acontece na maioria das empresas de produção de softwares que têm o código-fonte fechado. Esse modelo, Raymond (2004) denominou de Catedral.

Nesse contexto, o chavão libere cedo (uma versão do software) e, frequentemente, delegue tudo que você possa, esteja aberto ao ponto da promiscuidade chegou como um grande choque para o universo da engenharia de softwares complexos. Isso porque, no início do projeto Linux - por volta de 1991 -, a relação entre usuários e desenvolvedores de um projeto de software foi completamente alterada: com a disponibilização do código fonte na internet, muitos usurários passam a ser co-desenvolvedores eficazes. Linus Torvalds, fundador do projeto Linux, percebeu que muitos usuários são hackers também e, portanto, podem diagnosticar problemas, sugerir correções e ajudar a melhorar o código muito mais rapidamente do que um programador ou até mesmo uma equipe técnica de forma isolada, fechada. Em outras palavras, dados olhos suficientes, todos os erros são triviais (Raymond, 2004, p.01). 
Assim, nesse modelo aberto, não era estranho uma nova versão do Kernel ${ }^{4}$ Linux ser lançada mais de uma vez por dia.

Nenhuma catedral calma e respeitosa aqui -- ao invés, a comunidade Linux pareceu assemelhar-se a um grande e barulhento bazar de diferentes agendas e aproximações (adequadamente simbolizada pelos repositórios do Linux, que aceitariam submissões de qualquer pessoa) de onde um sistema coerente e estável poderia aparentemente emergir somente por uma sucessão de milagres (Raymond, 2004, p.01).

\section{GNOME: um "Bazar" Organizado?}

Envolvendo mais de 300 hackers de todos os cinco continentes do globo, o Projeto GNOME gira em torno de dois objetivos comuns, por meio exclusivo de um ambiente digital na internet. De um lado, tendo como foco o chamado "usuário final", o projeto visa o desenvolvimento de um ambiente de desktop para distribuições do GNU/Linux, com uma interface gráfica (Graphical User Interface - GUI) e um conjunto de aplicativos (softwares) que facilitem ao máximo a interação desse usuário com o computador (hardware). Por isso, de forma imbricada ao desenvolvimento desse ambiente gráfico GNOME, se faz presente também o processo de tradução dos softwares que compõem o desktop para mais de 60 idiomas no mundo, abrangendo, assim, desde idiomas ocidentais (como Espanhol, Francês e Português) que usam o mesmo alfabeto, como também línguas e dialetos que usam alfabetos completamente distintos - como, por exemplo, Chinês, Grego, Árabe, Hindi e Hebraico. Por outro lado, o projeto acaba

\footnotetext{
${ }^{4}$ O Kernel é muitas vezes descrito como o "sistema nervoso" de um sistema operacional para computadores, dada sua complexidade e funcionalidade. Assim, para muitos programadores e engenheiros computacionais, é praticamente impossível um técnico desenvolvê-lo de forma isolada em qualquer espaço de tempo.
} 
tendo também como foco a estruturação de uma plataforma de desenvolvimento, contendo uma coleção de Interfaces de Programação de Aplicativos (APIs), além de diversas ferramentas de programação, que são utilizadas por hackers tanto do projeto, como também de outras comunidades online de softwares (livres) espalhadas pelo ciberespaço.

Para dar conta desse complexo processo de produção de software, este "grande e barulhento bazar" acaba envolvendo desenvolvedores e colaboradores em geral, oriundos de 59 países dos cinco continentes do planeta. Mais especificamente, por meio da pesquisa realizada, pôde-se observar que dos 297 hackers catalogados (de janeiro a julho de 2006), quase a totalidade dos membros (99\%) da comunidade é do sexo masculino e a maioria (33\%) é de países da Europa Ocidental (como França, Inglaterra, Espanha e Alemanha), sendo outra boa parte (19\%) dos países da América do Norte (México, Canadá e EUA). A América do Sul (Chile, Brasil e Argentina) chega a representar $5 \%$ dos membros. No entanto, existem também pessoas de países africanos e asiáticos como Índia, Irã, China, Vietnã, Tunísia, Togo, Madagascar e África do Sul; além da Oceania que se faz presente por meio de países como, por exemplo, Austrália e Nova Zelândia.

Assim, segundo Aguiar (2007), após a conclusão de um ciclo semestral de produção e compartilhamento entre pares de ambiente digital internacional, o desktop (produto final da comunidade) passa a ser compartilhado livremente e, posteriormente, utilizado por diversas distribuições do sistema operacional GNU/Linux no mundo. Essas "distros" - como são chamadas pelos usuários - são desenvolvidas tanto por empresas (a exemplo do Ubuntu da empresa Canonical e do Oracle Solaris da multinacional Oracle), como por outras comunidades online espalhadas pela rede mundial de computadores. De acordo com as informações que constam no site do Projeto GNOME, mais de 140 distribuições diferentes do GNU/Linux no mundo adotam esse desktop livre. Como resultado desse processo mundial 
de distribuição, sem contar com a maioria dos usuários domésticos em todos os países que não são contabilizados, Aguiar (2008) ressalta que mais de 200 mil pessoas em Extremadura e Andaluzia, na Espanha, um milhão, na China, e 400 mil pessoas nos telecentros de São Paulo, no Brasil, usam o GNOME como o ambiente de desktop dos seus computadores.

\section{Hackerismo como uma ação (humana) paradoxal}

Segundo as análises de Benkler (2002), os resultados, a eficiência e a grande capacidade de inovação incorporadas ao processo de produção tecnológica pela experiência organizacional dos hackers colocam um enigma para as teorias clássicas das ciências sociais aplicadas (a exemplo da Teoria da Firma), como se pode observar pelo exemplo de produção colaborativa e não-contratual do projeto GNOME.

[P]rojetos de software livre não dependem de mercados nem de gestões hierárquicas para organizar sua produção. Programadores não participam de um projeto porque alguém que é seu chefe disse que era para ser feito. [...] A maioria dos processos de participação nos projetos não pode ser então explicada pela presença direta de um comando, de preço, ou de qualquer retorno monetário (Benkler, 2002, p. 373).

De forma contrária ao que descrevem autores como Ronald Coase em A Natureza da Firma, ao longo desse processo de produção mediado pelo computador, emerge, de forma espontânea e "auto-evolutiva", uma dinâmica de trabalho informal entre pares, mais elaborada e eficiente do que qualquer planejamento central e hierárquico poderia alcançar. Além disso, Eric Raymond (1999) afirma que os hackers são estimulados pelos interesses de poder e de reconhecimento individual, numa comunidade de pares onde suas paixões são simplesmente compartilhadas. Partindo dessa perspectiva, supõe-se que 
a 'função empreendedora' que os hackers do Linux (por exemplo) estão maximizando não é economia clássica, mas é a intangível satisfação do seu próprio ego e reputação entre outros hackers - Alguém pode chamar a sua motivação de 'altruísta', mas isso ignora o fato que altruísmo é, em si mesmo, uma forma de satisfação do ego para um altruísta (Raymond, 2004, p. 10).

Em outras palavras, essa relação paradoxal de "altruísmo" e "satisfação do ego" como uma forma de retorno do trabalho empreendido nesses projetos comunitários - como a do Kernel Linux ou do projeto GNOME - não flui, portanto, segundo os parâmetros econômicos do mercado ou de qualquer instituição contratual. Por outro lado, Benkler (2002), Hiamenm (2001), Castells (2003) e Raymond (1999) apontam para outro tipo de entendimento. Isto é, esses autores relatam que a dinâmica de trabalho empreendida pelos hackers, estando desvinculada de instituições compensatórias, requer outra forma de vínculo social e adesão a outro conjunto de valores que articula, ao mesmo tempo, a reputação entre os pares com o prazer e a alegria do ato de criar.

Dentre esses valores, segundo Stallman (2002), Castells (2003) e Silveira (2005), a liberdade (de ter acesso, de usar, de contribuir e redistribuir todo o conhecimento possível) é o valor supremo dos hackers. Essa liberdade parece traduzir-se em um jogo de reputações e troca entre pares, quando a lógica social passa a ser determinada não pelo retorno monetário ou pela acumulação de bens, mas sim pela informação, conhecimento ou código (de programação) que é doado. Em outras palavras, a dinâmica empreendida no seio da cultura hacker estaria, assim, associada a uma regra de ouro fundada na tripla ação de dar, receber e retribuir que Apgaua (2004), Castells (2003), Kollock (1999), Raymond (1999) e Barbrook (1998) denominaram de prática da cultura do dom que induziria a manifestação de uma suposta economia da dádiva (gift economy). 


\section{A dádiva na modernidade}

Felizmente, nem tudo está ainda classificado exclusivamente em termos de compra e venda. As coisas têm ainda um valor de sentimento para além do mundo venal (Mauss, 1989, p. 175).

Trazendo constatações como essa, lançadas ao universo das ciências humanas nas primeiras décadas do século XX através de sua obra Ensaio sobre a Dádiva, Marcel Mauss levanta o véu da incompreensão sobre aquilo que alguns pesquisadores considerariam - anos mais tarde - como um dos pilares de constituição das sociedades humanas: a tripla obrigação de dar, receber e retribuir ${ }^{5}$ ou, simplesmente, a dádiva.

Por meio da análise de uma série de pesquisas etnográficas associadas a diferentes povos das mais diversas regiões do globo (como Polinésia, Melanésia, Noroeste Americano e Austrália), Marcel Mauss desenvolveu um estudo sobre a forma e o sentido da circulação e da troca de bens em sociedades ditas "arcaicas" ou "primitivas". Após essa análise, Mauss rejeitou a possibilidade de compreender essas relações de troca sob a ótica utilitária do mercado, segundo a qual, indivíduos em condições de escassez trocariam exclusivamente bens e serviços para satisfação de suas necessidades elementares, constituindo uma espécie de "economia natural" ou um sistema de escambo. É ainda uma noção complexa a que inspira todos os atos econômicos que descrevemos; e essa noção não é nem a da prestação puramente livre e gratuita, nem a da produção e da troca puramente interessadas, do útil. É uma espécie de híbrido [...] (Mauss, 1950, p. 184). Dessa forma, inicialmente,

\footnotetext{
${ }^{5}$ Todavia, vale sublinhar que a distinção feita, inicialmente por Mauss, entre dar, receber e retribuir para expressar a tripla ação da dádiva é simplesmente de natureza analítica para explicar esse mesmo fenômeno. Numa relação de dádiva, a pessoa que doa algo pode estar, na verdade, retribuindo pelo fato de já ter recebido de terceiros. (em outro momento) ou de quem está sendo beneficiado por ela nesse determinado instante.
} 
M. Mauss nos tinha principalmente servido para sedimentar a crítica do utilitarismo e do economicismo, corroborando a intuição, por si mesma evidente, que na ação social, certamente, entra o cálculo e o interesse, material ou imaterial, mas não somente isso: encontra-se também obrigação, espontaneidade, amizade e solidariedade, em suma, a dádiva (Caillé, 2002, p. 15).

No entanto, trabalhos contemporâneos de pesquisa realizados por autores como Godbout (1999), Martins e Campos (2006) ressaltam que essa circulação de bens e serviços de base "gratuita", longe de ser um resíduo das sociedades tradicionais, é uma característica da sociedade moderna. Na sociedade contemporânea (ou sociedade em rede) assistese a um extenso leque de experiências ligadas a trabalhos voluntários e engajamentos associativos em todos os continentes do planeta. Seja no mundo marcado pela ineficiência do estado e do mercado na promoção do bem-estar social, seja num outro mundo que traz à tona as problemáticas relacionadas ao desenvolvimento exacerbado dessas instituições, outras formas de solidariedade e colaboração mútua se exprimem por meio de redes sociais, comunidades virtuais, associações e diversas atividades coletivas sem fins lucrativos. Em todos esses exemplos, quer se trate de um tipo tradicionalista ou moderno, é claro que o engajamento associativo e voluntário implica que a pessoa dê uma parcela de seu tempo e se empenhe pessoalmente em alguma tarefa (Caillé, 2002, p. 141).

\section{O GNOME e a dádiva mediada pela internet}

Dentro dessa perspectiva da dádiva entre os modernos, para aprofundar o entendimento sobre a essência do trabalho adotado pelos hackers no processo de produção colaborativa do Projeto GNOME, a pesquisa que fundamentou este texto supôs inicialmente que essa dinâmica 
de trabalho estaria, de forma geral, fundada em um tipo de engajamento eminentemente voluntário e não-contratual. Esse trabalho voluntário, segundo tal pressuposto teórico, não estaria sendo empreendido dentro de princípios instrumentais e individualistas, mas sob princípios de liberdade e obrigação intimamente imbricados, por meio dos quais se realiza um objetivo comum: o desenvolvimento e a distribuição de um sistema computacional livre. Isso, como afirma Caillé (2002), tendo em vista que os interesses de glória e prestígio, de ser, dominam hierarquicamente, tanto positiva como normativamente, os interesses instrumentais, de posse, os interesses do ter (Caillé, 2002, p. 145).

Assim, de acordo com tal concepção, a dádiva não é considerada como um objeto ou um bem doado; a dádiva é uma relação de troca em que o bem circula em nome ou a favor do vínculo entre os atores, entre um coletivo. Esse bem, que acaba servindo de "ponte" para a relação, pode ser tanto um objeto (material tangível) como também uma palavra, um gesto, uma ideia, um conhecimento ou um código-fonte. Assim, ao analisar a dinâmica de trabalho do projeto GNOME, partiu-se do princípio de que o trabalho hacker nessa organização poderia ser entendido por meio de uma teoria pluridimensional e paradoxal da ação humana - nos termos, portanto, da teoria antropológica da Dádiva. Tal teoria leva em consideração quatro dimensões da ação humana - interesse e desinteresse, obrigação e liberdade - irredutíveis umas às outras, no contexto do fato social analisado.

Assim, essa noção maussiana de dádiva parece nos abrir a possibilidade para a compreensão do processo de desenvolvimento colaborativo entre os hackers não como uma ação puramente altruística, mas como uma ação humana paradoxal, ao mesmo tempo, interessada e desinteressada, espontânea e obrigada (Caillé, 2002). Partindo desse entendimento, este texto adotou uma grade analítica (vide tabela 1) para facilitar o processo de entendimento da dinâmica social dos hackers no Projeto 
GNOME, à luz do conceito antropológico da Dádiva. Antes, porém, de adentrar na discussão sobre os resultados encontrados na pesquisa de campo, faz-se necessária a compreensão específica das dimensões e indicadores que compõem tal grade. Exclusivamente para fins didáticos, tais dimensões foram separadas e definidas, portanto, da seguinte forma:

Tabela - Grade Analítica.

\begin{tabular}{|c|c|c|}
\hline \multicolumn{3}{|c|}{ Grade Analítica } \\
\hline Conceito & Dimensões & Características/ Indicadores \\
\hline \multirow{19}{*}{ Dádiva } & \multirow{6}{*}{ Interesse } & Reconhecimento \\
\hline & & Diversão \\
\hline & & Prazer/ Paixão \\
\hline & & Poder (Meritocracia) \\
\hline & & Desafio/ Aprendizado Técnico \\
\hline & & Trabalhar Junto \\
\hline & \multirow{5}{*}{ Desinteresse } & Voluntário (não-remunerado) \\
\hline & & Compartilhamento/ Doação \\
\hline & & Gratuidade \\
\hline & & Espontaneidade/ Ações não calculadas \\
\hline & & "Causa"/Sentido da ação \\
\hline & \multirow{4}{*}{ Liberdade } & Relação não-contratual \\
\hline & & Trabalho no Tempo livre \\
\hline & & Autonomia Política (Decisão) \\
\hline & & Abertura para entrar e sair \\
\hline & \multirow{4}{*}{ Obrigação } & Sentimento de dívida \\
\hline & & Livre Retribuição \\
\hline & & Compromisso \\
\hline & & Regra Implícita \\
\hline
\end{tabular}


Interesse - para os maussianos, de maneira alguma a dádiva, como uma tipologia da ação humana, é desprovida de interesse. No entanto, segundo Caillé (2006), para trazer um mínimo de clareza a essa dimensão, é necessário distinguir o interesse por trás da ação humana segundo duas categorias: o "interesse em" e o "interesse por". O primeiro tem uma natureza instrumental, quando uma determinada ação é feita não porque se tem prazer em realizá-la, mas porque se tem interesse em fazê-la para alcançar outros fins, dentro de uma perspectiva utilitária. Por outro lado, quando se sente interesse por alguém ou por algo, a ação se efetua por si só, por paixão, tornando-se um fim em si mesma ${ }^{6}$. Partindo dessa distinção, pode-se dizer que a dádiva está ligada a uma ação que se efetua por si, mas que, ao mesmo tempo, acaba gerando prazer, criatividade, reconhecimento e prestígio. Este tipo de motivação, de interesse por, normalmente se manifesta em detrimento dos interesses instrumentais (interesse em) que visam, por exemplo, uma vantagem unilateral em oposição à relação que se estabelece. Partindo dessa distinção,

a dádiva não deve ser pensada sem interesse ou fora dele, mas contra o interesse instrumental (interesse em). Ela é o movimento que, para fins da aliança ou (de) criação, subordina os interesses instrumentais aos interesses não-instrumentais. Às paixões (Caillé, 2002, p. 145).

Desinteresse - se não existe dádiva desinteressada, por outro lado, existe desinteresse na dádiva. Assim, por mais que exista, por exemplo, interesse por um determinado engajamento voluntário, nesse tipo de trabalho não existe nenhum tipo de expectativa de remuneração (retorno)

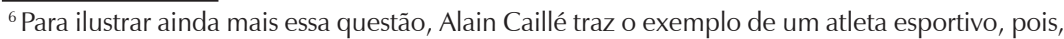
para o autor, antes de fazer do esporte seu ganha-pão, o jogador profissional se lança no jogo por paixão, por "interesse por". É difícil crer que ele continue a ser um bom jogador se vive a perder todo o prazer no jogo, mas ele só será um bom profissional, se subordinar o interesse por ao interesse em (Caillé, 2006, p.57).
} 
monetário direto. Além disso, esse tipo de dinâmica social não acontece por meio de ações calculadas (decisões) entre "prós" e "contras", mas por ações espontâneas, impulsionadas muitas vezes por motivações que não são bem compreendidas por quem as executa.

Nesse sentido, a dádiva se opõe radicalmente ao cálculo, a essa forma particular, e não-universal, de se comportar. Assim, não haveria somente o cálculo, de um lado, e reflexo do tipo animal do outro. Há o gesto feito no espírito da dádiva (Godbout, 1999, p. 116).

Liberdade - diferentemente das relações que permeiam as esferas do Estado ou do mercado, em um circuito de dádiva não há qualquer tipo de acordo expresso ou contrato formal entre indivíduos motivados por interesses particulares que obrigue alguém a dar, receber ou retribuir alguma coisa. Além disso, Godbout (1999) ressalta que, na sociedade moderna, o grau significativo de obrigação social, isto é, de algo feito por obrigação, tradição ou costume, parece ser cada vez mais raro. O que predomina numa relação social de dádiva é, portanto, a livre entrada e saída.

Assim, constatamos que os atores da dádiva introduzem, de forma voluntária e permanente, uma incerteza, uma indeterminação [...] a fim de se afastarem o máximo possível do contrato, do compromisso contratual (mercantil ou social), assim como da regra do dever; de fato de qualquer regra do tipo universal (Gobbout 2002, p.76).

Obrigação - Por outro lado, como já foi ressaltado neste artigo, a liberdade em um sistema de dádiva não se manifesta - em qualquer hipótese - pela liquidação do sentimento de dívida (diferentemente de uma relação mercantil). Essa condição torna a saída (descompromisso) do ator algo não tão simples de ser concretizado, apesar da sua condição de liberdade. Por isso, Caillé (2002) e Gobbout (1999) demonstram que, seja em sociedades tradicionais ou contemporâneas, um dos eixos vitais de qualquer sistema de dádiva é a presença do sentimento intrínseco de 
obrigação, de endividamento. Para compreendê-lo, faz-se necessário ir além da noção de obrigação como algo externo, enrijecido sob a forma de regra social positivada, legal, tradicional ou racional, pois esse sistema não impõe uma obrigação contratual, sob a forma de dívida, como poderia se fazer presente na perspectiva do mercado. A 'verdadeira' dádiva é um gesto socialmente espontâneo, um movimento impossível de captar em movimento, uma obrigação que o doador dá a si mesmo, mas uma obrigação interna, imanente (Godbout, 1998, p. 47). Por isso, a dádiva é também considerada um jogo constante entre obrigação e liberdade.

\section{Um trabalho a troco de nada?}

Dentro desse contexto, uma questão se torna recorrente ao se deparar com a intrigante dinâmica social empreendida pelos hackers de uma comunidade online de software: por que compartilhar? Ou ainda, utilizando o questionamento elaborado por Bill Gates na sua carta, intitulada de Open letter to hobbyists: quem pode se permitir fazer um trabalho profissional a troco de nada?

No entanto, mais recorrente do que esse tipo de pergunta é o tipo de resposta comum (e apressada) hoje oferecida para o entendimento desse fenômeno social. No âmbito do atual postulado utilitarista dominante nas ciências humanas aplicadas, o engajamento voluntário de pessoas em um processo de produção - como aquele desenvolvido no universo das comunidades online de software livre - partiria de três premissas da satisfação individual de desejos (utilidade) do indivíduo, a exemplo do que sugerem McKenzie e Lee (2006). Em primeiro lugar, que o indivíduo tem uma preferência e pode identificar, dentro de limites, o que deseja. Assim, conform a segunda premissa, o indivíduo é capaz de ordenar seus desejos consistentemente, da maior à menor preferência. E, por fim, o indivíduo escolherá dentre essas preferências a que maximizará sua satisfação. 
A partir de tais postulados, de fato, como demonstrou Godbout (2002), torna-se muito difícil para um indivíduo moderno conseguir compreender a natureza de um sistema de trabalho e produção de bens e serviços desse tipo, já que todo esforço nesta direção implica a exposição dos limites inerentes ao postulado utilitarista dominante. Como foi frisado na introdução, outro bom exemplo dessa dificuldade de entendimento ocorreu em entrevista realizada pelo apresentador Jô Soares, num programa de televisão de audiência nacional, no Brasil. Ao ser informado, por um professor universitário que colabora com algumas comunidades de software livre sobre esse engajamento voluntário dos hackers, o apresentador logo afirmou: não adianta vir com esse papo que é de graça, porque há uma intenção anterior de vender isso!!

Para além de interpretações desse tipo, ao observarmos o cotidiano de uma comunidade online de software livre, como a do Projeto GNO$\mathrm{ME}$, outras respostas surgem no horizonte. Basta, de início, uma simples observação do perfil dos membros presentes em uma das inúmeras salas virtuais de "bate-papo" (chats) do Projeto e nos blogs (http://planet. gnome.org) para se perceber algo de inusitado em comparação a qualquer organização formal que produz e distribui softwares: boa parte dos hackers voluntários trabalham formalmente durante a semana em outras instituições (sem relação com o Projeto Gnome) e, portanto, dedicam-se ao Projeto no período que eles definem como "tempo livre". Porém, o que significa, na prática, esse "tempo livre"? Segundo Jeff Waugh, um dos membros do Time de Lançamento de Versão (Release Team) em 2006, isso significa o tempo que meu emprego e Pia (esposa) não demandam de mim, sempre em detrimento do meu 'padrão de sono'7 [Tradução nossa]. Numa perspectiva utilitarista, torna-se irracional ou incompreensível o

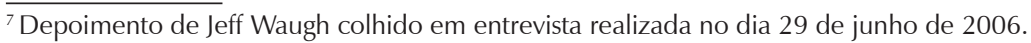


comportamento de Waugh, pois, além de gastar seu tempo livre para trabalhar mais (e não ganhar com isso), ele ainda compromete a estabilidade da sua relação matrimonial.

Além disso, esse "tempo livre" dedicado ao trabalho no Projeto também pode significar uma extrapolação, em alguns casos, de certos limites de tempo de trabalho. Conforme as palavras do hacker Guilherme Pastore ${ }^{8}$, isso pode significar uma dedicação durante o "tempo que não deveria ser livre", já que utiliza parcelas de tempo de outros "contratos". No entanto, essa situação de se dedicar além do tempo livre disponível não é algo que acontece somente no projeto GNOME. De acordo com os dados encontrados numa pesquisa aplicada por Lakhani e Wolf (2005) junto a 684 hackers de 287 diferentes Projetos de software livre, 87 \% dos hackers trabalhavam de forma voluntária. Por outro lado, 55\% dos hackers entrevistados disseram contribuir durante seu horário de trabalho formal (em outras instituições). Quando a pesquisa questionou se o supervisor do setor onde o hacker trabalha formalmente (em outra instituição) tinha consciência deste "trabalho extra", 38\% disseram que não - ou seja, 38\% afirmaram trabalhar, de fato, num tempo que não deveria ser livre. Partindo dessa perspectiva, a questão inicial proposta por Bill Gattes dever ser significativamente alterada. O que se quer saber é, na verdade: por que os hackers que trabalham de forma voluntária (não-contratual) no GNOME dedicam seu tempo livre e ainda parte do "tempo que não deveria ser livre"?

\footnotetext{
${ }^{8}$ Guilherme Pastore, mais conhecido na comunidade GNOME pelo apelido "Fatalerror", é desenvolvedor do Projeto Internacional e um dos líderes do Projeto Brasileiro de Tradução. Ele nasceu no Brasil em plena década de 90, o que significa que ele tinha apenas 16 anos na época da entrevista, em 2006. ressaltar ainda que, além de participar do Projeto GNOME, Guilherme era o hacker mais novo do mundo a fazer parte do time de desenvolvedores da comunidade do sistema operacional Debian.
} 


\section{$10 \mathrm{O}$ interesse por trabalhar junto}

Partindo dos resultados encontrados na pesquisa realizada por Lakhani e Wolf (2005), pode-se dizer que a principal motivação por trás do trabalho voluntário empreendido pelos hackers está, em geral, relacionada ao fato dessa ação de desenvolvimento de códigos ser intelectualmente estimulante e prazerosa para eles. De fato, esse interesse por fazer algo pessoalmente estimulante se faz presente também na comunidade GNOME. No entanto, ao reproduzir essa questão de forma aberta, dentro de uma entrevista semi-estruturada, sem questões objetivas, surge outra reposta (ainda não presente em outras pesquisas sobre software livre) comum a todos os entrevistados: "as pessoas". De acordo com as palavras do próprio Guilherme Pastore, um dos hackers mais novos dessa comunidade, isso significa dizer que ele dedica seu tempo livre (e o que não deveria ser livre)

por me sentir parte da comunidade, por causa dos laços de amizade, da identificação com os ideais do projeto. Isto faz você gostar do projeto de uma forma que você quer dedicar (doar) seu tempo naquilo. As pessoas não levam as coisas tão a sério. Trabalhar no GNOME é divertido, não só por causa do código que eu gosto de fazer naturalmente, mas por causa das pessoas envolvidas e por causa do tratamento que você tem com elas (Entrevista com Guilherme Pastore.).

Esse depoimento é bem representativo para os resultados dessa pesquisa, pois - sem negar o interesse por trabalhar em algo estimulante, divertido e prazeroso - esse garoto de dezesseis anos demonstra a importância do vínculo estabelecido com os outros membros da comunidade. Além dele, em todas as entrevistas realizadas, mesmo que algumas respostas em geral ainda tragam motivações de ordem técnica, a dimensão social dos vínculos sempre aparece, na verdade, como uma razão fundamental. Em outras palavras, isso significa que o que leva os hackers desse projeto a se engajarem é, conforme o relato de Waugh, a incomparável 
combinação entre uma filosofia moral e uma filosofia técnica, junto, é claro, com a comunidade e as pessoas incríveis de lá [Tradução nossa]. Ou ainda, segundo o desenvolvedor Glyn Foster, pode-se dizer que:

o projeto está dividido em duas coisas: obviamente é o desktop livre, o código aberto, a base de tudo. Do outro lado, você tem pessoas muito, muito interessantes e isso é fascinante, poder encontrar amigos por lá, ainda mais se você fizer projetos por diversão. Eu acho que é uma das melhores coisas a que eu realmente posso dedicar a minha vida. Eu acredito que é uma boa causa. E eu penso que é muito legal para eu conhecer pessoas de várias partes do mundo (Entrevista com Glyn Foster).

Partindo dessa constatação, ao procurar compreender a lógica de trabalho que dá vida ao projeto GNOME, percebe-se claramente que o trabalho empreendido pelos hackers não é feito a troco de nada. Existe um retorno. No entanto, sem considerar os motivos sociais, é muito difícil compreender os motivos que levam os hackers a empregar seu tempo livre no desenvolvimento de programas que são dados a terceiros posteriormente (Himanem, 2001). Para compreender esse "trabalho a troco de nada" é preciso entender, portanto, que o fator organizacional dessa comunidade online de software livre não está associado nem ao dinheiro, nem à acumulação de bens; mas à paixão e ao prazer de criar, juntos, algo que seja reconhecidamente valioso entre seus pares, em termos tecnológicos e sociais.

De modo ainda mais específico, pode-se dizer que os membros do projeto GNOME se engajam na comunidade porque têm interesse por desenvolver códigos, por contribuir com um Projeto dessa natureza. Além disso, o envolvimento social nesse trabalho coletivo (realizado junto com outros hackers) acaba proporcionado reconhecimento, prestígio, prazer, criatividade e, por conseguinte, poder (mérito) atribuído a cada importante contribuição técnica compartilhada. Além da paixão e do prazer pela atividade em si, outros "retornos" são gerados pelo fato de se trabalhar junto, de se estabelecer vínculos sociais em um grupo por meio do código com- 
partilhado. Até porque, se essa ação de dar, receber e retribuir representa uma forma original e distinta de produção e circulação de bens, como se nos mostra, ela não se manifesta na ausência de um retorno contratual. Ao contrário: como apontam Mauss (1998), Caillé (2004) e Godbout, (1999) em um sistema de dádivas como esse, o retorno existe, mesmo que não tenha sido desejado. Mais ainda, pode-se dizer que a única coisa não-livre num ciclo como esse é o fato de se ter que receber. Se ele não existir, será um trabalho que não deu certo, e quem dá sente-se "traído", frustrado.

Porém, para entender essas dimensões, é fundamental a ampliação do entendimento sobre o que possa ser um "retorno", para muito além da perspectiva mercadológica, financeira e contratual. Em outras palavras, devese considerar como retorno desde a própria satisfação ou prazer que esse trabalho mediado por computador pode representar, até o reconhecimento e o prestígio ligados a ele. Por isso, o termo "comunidade voluntária de interesse", cunhada por Eric Raymond (2004), é uma expressão paradoxal e, ao mesmo tempo, bem precisa para representar a dinâmica social empreendida nessa organização por meio da rede mundial de computadores.

\section{A gratuidade e a espontaneidade}

Por outro lado, se não existe ação voluntária desinteressada, existe também desinteresse nas ações empreendidas pelos membros do Projeto GNOME. Afinal, mesmo que existam interesses por este trabalho, nesse tipo de engajamento, em geral, não existe uma expectativa concreta de remuneração ${ }^{9}$ ou algum tipo de cálculo, estipulado em contrato, sobre

\footnotetext{
${ }^{9}$ Vale frisar que, apesar de não existir uma expectativa de remuneração, isso não significa dizer que, caso ela aconteça, não seja vista com bons olhos para qualquer membro da comunidade. Apesar de não existir uma expectativa direta de remuneração sobre o trabalho doado, pode-se dizer que o sonho de muitos hackers voluntários da comunidade é poder ser remunerado e, assim, dedicar a maior parte possível do seu tempo ao Projeto.
} 
a quantidade de trabalho despendido. Sem esse cálculo sobre quanto (tempo) se trabalha, por conseguinte, não há também uma contabilização sobre algum tipo de retorno financeiro direto, isto é, sobre quanto se deve receber em troca. Quando questionado, por exemplo, sobre quando e como se dedica ao projeto, Vincent Untz, um dos membros voluntários mais ativos e respeitados do Projeto, respondeu: você pensa que isto é fácil de responder? Quando e como? (risos...) Na maioria das vezes, no meu tempo livre. Como? É no meu tempo livre então eu faço o que eu quiser.

Além de agirem de forma não contratual e não-calculada, alguns hackers ainda ressaltam a importância para eles de se contribuir com "algo maior", com uma "causa" que beneficie outras pessoas. Ou seja, segundo as palavras de Elijah Newren - então gerente de lançamento de versões (Release Manager) do Projeto -, o que o mantém trabalhando voluntariamente no projeto é, portanto, essa incrível comunidade com muitos amigos legais; saber que minhas contribuições estão beneficiando a vida cotidiana de muitas pessoas [Tradução nossa]. Partindo de tal constatação, esta análise considera que o código ou trabalho dado, recebido e retribuído é uma ação, ao mesmo tempo, interessada e gratuita. Ou ainda, de forma mais simplificada pelas palavras de Davyd Madeley (outro desenvolvedor efetivo do projeto), é algo que emana, em primeiro lugar,

por causa das pessoas. Eu tenho feito alguns amigos verdadeiros na comunidade GNOME. Eu também gosto do momento quando um projeto realmente começa a andar unido. Finalmente, é legal receber agradecimentos dos usuários pelo trabalho que vocêfaz, e saber que essa é uma pequena maneira de você ajudar a transformar o mundo num lugar melhor (Entrevista com Davyd Madeley).

Em outras palavras, pode-se dizer também que tal engajamento é uma doação não-calculada, mas socialmente interessada. É algo que acaba circulando, portanto, em função do laço social (mesmo mediado por computador), tanto para romper o isolamento, como para dar sentido e 
identidade a uma "causa", um trabalho não-contratual e espontâneo, empreendido por meio dos liames digitais da Internet. Afinal, mesmo numa comunidade on-line como a GNOME,

os seres humanos são, e sempre foram, seres motivados de diversas maneiras. Nós agimos de forma instrumental, mas também de forma não-instrumental. Nós agimos por ganho material, mas também por bem estar psicológico e gratificação, e por união social. Não há nada de novo ou extraordinário nisso, exceto talvez para alguns economistas (Benkler, 2006, p. 06) [Tradução nossa].

\section{Hackers voluntários e profissionais: interesse versus gratuidade?}

Apesar de o voluntariado ser uma relação de trabalho predominante dentro dos projetos de software livre, muitos hackers são pagos diretamente (por empresas de $\mathrm{TI}$, governos e fundações de todo o mundo) para manterem o desenvolvimento de determinados sistemas ou aplicativos tecnológicos livres. Segundo os dados da pesquisa de Lakhani e Wolf (2005), na amostra de 684 hackers que atuam em diferentes projetos, esses profissionais representam $13 \%$ do total. Além disso, o número deles pode aumentar - chegando a $40 \%$ - se forem considerados ainda os hackers que trabalham no tempo que "não deveria ser livre", isto é, se a pesquisa levar em consideração os hackers que fazem seu trabalho voluntário durante seu expediente de trabalho remunerado. Assim como a maioria das comunidades online de software livre, o projeto GNOME é composto tanto por membros voluntários como por técnicos que são pagos para trabalharem no desenvolvimento de alguma aplicação ou parte específica do sistema. De acordo com a amostra de 297 membros catalogada para este trabalho, o percentual de pessoas remuneradas chega a $15 \%$ dos pesquisados. 
Se indagarmo-nos sobre um presumível conflito entre hackers voluntários e profissionais, tal situação não foi constatada na pesquisa. De fato, esse tipo de conflito não tem muita expressão na dinâmica de trabalho da comunidade GNOME. Em primeiro lugar, ao se adentrar o ambiente digital da comunidade (Blogs, listas de emails, IRCs), é muito difícil perceber uma diferença aparente no comportamento entre os membros voluntários e os remunerados. Apenas quando se observa o sistema de controle de versão (CVS) ou o sistema de controle de qualidade ("Bugzilla") do projeto é que se pode perceber uma primeira diferença: por terem mais tempo disponível para programar, as contribuições de código dos desenvolvedores remunerados, na maioria das vezes, são bastante significativas. Além disso, é comum hackers remunerados serem mantenedores de mais de um módulo do Projeto. De acordo com o hacker Glynn Foster, pode-se dizer que é muito mais fácil para os desenvolvedores pagos ficarem mais envolvidos no projeto e conseguir realmente acompanhar mais de perto.

Por outro lado, ao estarem submetidos também à pressão de normas, prazos e resultados impostos pelas empresas contratantes, alguns hackers remunerados não comunicam aos demais membros da comunidade o que eles estão produzindo nas suas respectivas empresas, seja em termos de correção de erros como também de acréscimos de novas funcionalidades para os softwares contidos no Projeto. Com essa postura mais "funcional", eles apenas compartilham essas informações quando a solução já está acabada. Dessa forma, por mais que depois toda a comunidade tenha acesso total aos códigos produzidos pelo programador contratado pela empresa, esse tipo de desenvolvimento, empreendido de forma "fechada", não é bem-visto por alguns membros voluntários da comunidade. Afinal, esse tipo de contribuição, que não parte de um processo dialógico com a comunidade, pode gerar situações de "retrabalho" (ou seja, quando duas ou mais pessoas estão fazendo a mesma atividade 
sem se comunicarem, duplicando esforços sem necessidade); ou de mudanças abruptas que impactam todo projeto e dificultam tecnicamente a incorporação de tal contribuição.

Contudo, mesmo com essas diferenças pontuais de tempo e de forma de dedicação ao projeto, no final, não se percebe nenhum tipo de conflito ou divergência mais significativa entre membros remunerados e voluntários. Ao contrário, o que se percebe é uma mudança de relação de alguns desenvolvedores pagos, a partir do momento em que eles passam a contribuir com o projeto e se envolver mais efetivamente. Assim como foi demonstrado no levantamento de Lakhani e Wolf (2005), em outros projetos de software livre, muitos hackers que tiveram um contato inicial com GNOME por meio de uma empresa de TI, acabaram, posteriormente, se envolvendo com outras atividades (extras) na comunidade, para além daquelas acordadas no seu contrato de trabalho.

Rompendo com uma perspectiva absolutamente funcionalista, boa parte dos hackers pagos passa a ter uma relação de trabalho "híbrida" com a comunidade. Isso demonstra que, sem negar a importância dos motivos utilitários da sua relação de assalariado, eles também trabalham voluntariamente em outras atividades não-contratuais, seja no seu tempo livre fora da empresa, seja no seu "tempo que não deveria ser livre" dentro da empresa. Conforme explica um dos desenvolvedores pagos do projeto,

às vezes, eu troco horas de trabalho formal que estou fazendo no GNOME por horas de trabalho livre em que tenho prazer. Mas, às vezes, é difícil para decidir as coisas que vou fazer no meu tempo de trabalho da empresa e no meu tempo livre. E a minha namorada está sempre chateada porque eu sempre estou com meu computador durante toda a minha semana [..]) Mas às vezes são coisas que você tem que fazer no seu tempo livre (Desenvolvedor entrevistado).

Partindo dessa dinâmica plural de trabalho, da mesma forma que não se pode, de maneira simplista, considerar que um desenvolvedor não-remunerado é desprovido de qualquer interesse, também é equi- 
vocado partir do entendimento de que um hacker remunerado dentro do Projeto GNOME é regido apenas por motivos utilitários e funcionais. Antes de tudo, porque, mesmo se submetendo a um contrato de trabalho formal, todos os códigos compartilhados por esses hackers não são da empresa contratante. Na visão dos hackers que participam do Projeto, o mérito da contribuição desenvolvida e disponibilizada na Internet está associado ao nome do hacker que a implementou, estando ou não tal contribuição registrada na licença de uso do software. Dessa forma, o vínculo não se estabelece entre a empresa e a comunidade, mas sim entre o hacker "funcionário" e a comunidade. Com isso, esse vínculo e o nível de envolvimento desse profissional com a comunidade transcendem a mera prestação de serviço. Em outras palavras, o hacker empregado acaba adotando um padrão de engajamento e relacionamento muito próximo a, ou perfeitamente compatível com, o dos membros voluntários, em relação ao trabalho desenvolvido no Projeto.

\section{A obrigação não-contratual de contribuir}

Dentre essas peculiaridades de comportamento observadas entre os desenvolvedores pagos que atuam no Projeto GNOME, uma em particular contraria ainda mais a noção de uma racionalidade utilitária e, até mesmo, a própria noção de contrato social (de trabalho) concebida originalmente por filósofos iluministas do século XVIII ${ }^{10}$, reforçando a importância da crítica teórica anti-utilistarista formulada em termos de teoria

\footnotetext{
${ }^{10}$ Segundo França Filho e Dzimira (1999), os filósofos iluministas (como Jonh Lock, Hobbes e Rousseau) conceberam o contrato social como uma espécie de acordo realizado entre indivíduos racionais, motivados por interesses instrumentais e particulares, ou seja, dentro de uma lógica puramente utilitária. Assim, de acordo com essa visão iluminista, se a oposição dos interesses particulares tornou necessário o estabelecimento das sociedades, é o acordo desses mesmos interesses que a tornou possível (Rousseau, 1989, apud França Filho e Dzimira, 1999, p. 177).
} 
da dádiva que fundamenta nossa análise neste texto. Em outras palavras, tendo como base a questão do "problema do último período" definida por McKenzie e Lee (2006), o que se pode esperar em termos de escolhas de um indivíduo (despedido) que tem o contrato de trabalho encerrado com o projeto GNOME? Dentro das premissas de uma ação racional e utilitária, McKenzie e Lee (2006) assinalam que existe, nesse período de final de contrato assalariado, uma tendência natural para ações oportunistas entre as partes (empregado e empregador). Mais ainda, para os autores, esse período pode resultar num forte incentivo para que o "futuro ex-empregado" trapaceie de forma oportunista a firma, com o intuito de maximizar vantagens em relação ao empregador.

No entanto, em contraposição a esse postulado, o que pôde ser observado no Projeto GNOME aponta, de forma paradoxal, para algo bem distinto. Isso porque, a partir do momento em que profissionais "híbridos" deixam de ser contratados pela empresa e, mesmo assim, continuam trabaIhando no Projeto de forma não-contratual e voluntária (muitas vezes até na mesma atividade que desempenhavam como assalariados), evidenciase mais uma intrigante questão para as ciências humanas no seio dessa dinâmica social contemporânea. Um dos exemplos dessa situação pode ser demonstrado quando, no ano de 2001, o então gestor (remunerado) das correções de erros ("bugs") de uma das ferramentas mais usadas no desktop do GNOME - o software Evolution ${ }^{11}$-, permaneceu no projeto como voluntário após deixar a empresa que o contratou para desempenhar essa função. Após romper com o contrato de trabalho assalariado, e mesmo continuando a trabalhar apenas no seu tempo livre, esse hacker (conhecido como Luis Villa) passou a contribuir não apenas na gestão de erros e falhas

\footnotetext{
${ }^{11} \mathrm{O}$ Evolution é um aplicativo (software) livre oficial do projeto GNOME que compõe o sistema de desktop, utilizado para gerenciar o correio eletrônico (emails), calendário e catálogo de endereços dos usuários.
} 
do Evolution, mas sim do Projeto GNOME como um todo. Devido a esse nível de contribuição e engajamento ainda dado por ele para a comunidade, hoje, além de ser um dos hackers mais respeitados na comunidade, Luis Villa é considerado o bugmaster emérito do Projeto.

Para entender o que leva, sobretudo um ex-trabalhador assalariado, a continuar engajado num mesmo projeto digital como voluntário (desempenhando mais tarefas do que aquelas inicialmente previstas no seu contrato de trabalho original!) basta entender que, assim como foi demonstrado no depoimento da maioria dos hackers voluntários e é frisado por Luis Villa,

a melhor parte (no Projeto GNOME) é o senso de camaradagem: nós estamos sempre juntos nisto, e eles são uma galera muito legal. Eu nunca trabalhei num projeto com uma equipe de trabalho melhor, no sentido que todos estão indo juntos a algum lugar, fazendo alguma coisa juntos, especialmente em torno do GNOME. Isto é de longe a forma de trabalho mais encantadora que as pessoas podem ter. $E$ eu nunca encontraria uma situação como esta, a não ser com muita sorte.

Tendo como base esse tipo de sentimento entre os membros, a comunidade GNOME representa uma intensa rede social mediada por computadores, constituída da soma das relações singulares que cada membro mantém com o grupo. Por isso, esse mesmo ambiente digital de interação social acaba também induzindo uma espécie de envolvimento paradoxal: ao mesmo tempo em que se engajam de forma prazerosa e espontânea (não-contratual), as pessoas que trabalham nesse grupo se envolvem de tal forma que se sentem socialmente responsáveis ou comprometidas com a comunidade. Muito além de um compromisso contratual (formal), esse sentimento de "endividamento" com o grupo e com o Projeto é algo que o hacker parece dar livremente a si mesmo - por mais paradoxal que isso seja. Afinal, não por acaso, contribuir voluntariamente com o GNO- 
ME significa também algo que proporciona a feliz sensação de devolver para a comunidade o que ela te deu: toda liberdade que ela te deu; e o código que ela te deu para você usar - reafirma, Luis Villa.

Porém, mais do que uma simples sensação de obrigação pessoal, esse sentimento implícito de endividamento sugere, assim, uma resposta para outra importante questão: como essas pessoas conseguem manter, sem nenhum tipo de contrato formal, vínculos mediados apenas por computadores e, ao mesmo tempo, garantir a sinergia de um processo de produção tecnológico altamente complexo, num âmbito multinacional? Mesmo tendo a Fundação GNOME como um projeto formal de apoio, todo o processo de desenvolvimento da plataforma e do desktop é completamente informal, isto é, não-contratual. Do ponto de vista institucional, isso quer dizer que todos os participantes (com exceção da diretoria da Fundação) não têm nenhum tipo de "dever" legal para com as atividades do Projeto.

Partindo dessa constatação, demonstra-se que a dinâmica social de trabalho da comunidade GNOME possui, de forma perene e implícita, algumas normas próprias, contudo, irredutíveis às dimensões contratuais do estado ou do mercado. Mais precisamente, para além da responsabilidade formal definida contratualmente, nessa organização, se sobrepõe uma responsabilidade não-contratual dos vínculos. Da mesma forma que os vínculos estabelecidos entre os membros do grupo são a razão de muitos hackers voluntários dedicarem ao projeto seu tempo livre (e não-livre!), esses mesmos vínculos podem de tal forma envolvê-los que, em muitos casos, os próprios membros se "obrigam" livremente entre si. Além disso, como um tipo de efeito nocivo dessa paradoxal condição, Luis Villa diz ainda que

o lado negativo (do Projeto GNOME) é que é muito fácil ser tomado pelo grupo. Por exemplo, nos últimos dois anos eu não fiz nada a não ser comer, dormir e trabalhar com este grupo. O grupo foi uma das duas melhores coisas (neste período). De maneira geral, o fato é que nós estamos tão 
estreitamente ligados que pessoas de fora dificilmente entendem como nós pensamos, e (assim) nós começamos a interagir mais friamente com essas pessoas de fora ("outsiders"). Eu acho que a gente realmente deveria evitar este problema (Entrevista com Luiz Villa).

De forma muito mais intensa e velada, esse fenômeno de tornar um determinado hacker um indivíduo "tomado" pelo grupo acaba, por fim, simbolizando uma obrigação às vezes até nociva, porém livremente contraída, a partir do momento em que ele se engaja e interage com esse Projeto. Dito de outra maneira, essa responsabilidade espontaneamente contraída significa para o hacker uma espécie de (não-)contrato livremente adquirido, porém simbolicamente mais "obrigante" do que um contrato de trabalho formal. Uma intensa relação social, quase que exclusivamente mediada por computador, que convida, portanto, a compreender o engajamento voluntário dos hackers não como uma ação puramente desinteressada e espontânea (livre), mas como uma ação paradoxal e complexa, ao mesmo tempo interessada e desinteressada, livre e obrigada - ou mais especificamente, como um sistema de dádivas mediadas pela internet.

Dessa forma, a autenticidade desse trabalho não-contratual se expressa como um gesto socialmente livre e contraditório, uma obrigação que o hacker dá a si mesmo, de forma pessoal e perene. No entanto, assim como alerta Godbout (1999), algumas metamorfoses na essência desse movimento podem alterar seu sentido. Isto é, esse movimento intrínseco pode se tornar preso e enrijecido num dever, pode se transformar muitas vezes em obrigação externa quando o próprio doador assim o faz. Nem todos aqueles que se engajam em projetos como esse são suficientemente fiéis aos próprios sentimentos para obedecer a esse movimento sem transformá-lo de algum modo em regra, em obrigação externa ou até mesmo em um contrato formal. 
Alguns pesquisadores maussianos sugerem que é nesse ponto, imerso nessa tensão, nesse jogo subjetivo entre espontaneidade e dever, gratuidade e interesse que se situa um fenômeno social intrigante denominado de "dádiva". Por causa dessa condição particular, segundo eles, pode-se afirmar que, mesmo num ambiente digital, em que as relações humanas são mediadas por computador,

a dádiva seria uma experiência em que a distância entre fins e meios é abolida, em que não há mais fins e meios, mas um ato que preenche o espaço de significação do sujeito e faz com que sejamos ultrapassados pelo que passa por nós, e pelo que se passa em nós. A dádiva seria uma experiência de abandono à incondicionalidade, experiência de pertencer a uma comunidade que, longe de limitar a personalidade de cada um, ao contrário, a expande. Contrariamente a uma visão individualista, a experiência da solidariedade comunitária não contradiz necessariamente a afirmação da identidade e pode, ao contrário, desenvolvê-la (Donati, 1995).

A dádiva seria, assim, uma experiência social fundamental no sentido literal, de experiência dos fundamentos da sociedade, daquilo que nos liga a ela para além das regras cristalizadas e institucionalizadas como normas da justiça (Godbout, 1998, p. 49).

\section{Considerações finais e novos horizontes para a Sociedade em Rede}

De fato, este texto se colocou uma tarefa desafiadora: compreender a natureza singular do trabalho em uma comunidade de hackers. A pesquisa empírica trouxe à tona o caráter complexo do processo de engajamento dos seus membros. Tal complexidade parece incompreensível sem um quadro de análise e referencial conceitual suficientemente amplo e atualizado para interpretá-lo. Assim, como sinalizaram Apgaua (2004), 
Castells (2003), Kollock (1999), Raymond (1999) e Barbrook (1998), compreende-se melhor o engajamento empreendido no seio da comunidade do projeto GNOME quando associado a uma "regra de ouro" fundada na tripla ação de dar, receber e retribuir. Ou seja, pode-se afirmar que a opção por uma leitura do fenômeno em termos de teoria da dádiva conferiu-lhe inteligibilidade, especialmente ao traduzir a complexidade do engajamento das pessoas neste tipo de comunidade por meio de um duplo paradoxo orientador da conduta dos sujeitos. O primeiro é aquele de uma ação simultaneamente livre e obrigada, pois as pessoas se obrigam a realizar um trabalho através da obediência às regras que elas próprias livremente se auto-impuseram e cuja liberdade de saída está sempre presente. O segundo paradoxo é aquele de uma motivação simultaneamente interessada e desinteressada, no sentido de o engajamento dos sujeitos no trabalho conter elevado nível de gratificação - embora não monetária ou material - baseada no próprio prazer do trabalho em si e no fato de estar junto ou fazer parte de um grupo, que permite, aliás, um forte exercício de criatividade e gera reconhecimento entre seus pares. No fundo, a problemática aqui abordada é aquela da própria construção do vínculo entre as pessoas, no sentido de interrogarmo-nos sobre as razões que levam tais sujeitos a se associarem no contexto deste empreendimento colaborativo. Trata-se, portanto, de um problema seminal do ponto de vista de uma teoria sociológica, o que parece justificar a fecundidade da teoria da dádiva nesta pesquisa.

Todavia, na visão de autores como Benkler (2006) e Aguiar (2009), as comunidades de software livre são apenas um exemplo proeminente de um fenômeno muito mais amplo na Sociedade em Rede. Para além do desenvolvimento de códigos abertos, a ética de trabalho que se manifesta na cultura de compartilhamento dos hackers, influencia e parece reconfigurar a forma de produção e distribuição da informação na economia contemporânea. Assim, a questão ilustrada por Bill Gattes e Jô Soares, que 
mobilizou o presente artigo, intrigando qualquer postulado dominante, pode ser reformulada e novamente apresentada da seguinte forma:

\begin{abstract}
por que cinquenta mil voluntários podem, com sucesso, ser co-autores da Wikipedia, a mais séria alternativa online da Enciclopédia Britânica, e depois entregar a obra de graça? Por que 4.5 milhões de voluntários contribuem com o que sobra do ciclo computacional de seus computadores para criar o mais poderoso computador da Terra,SETI@Home? (Benkler, 2006, p.06) [Tradução nossa]
\end{abstract}

Genauto Carvalho de França Filho - Doutor em Sociologia pela Université de Paris VII (França). Professor do Departamento de Estudos Organizacionais, na Escola de Administração da Universidade Federal da Bahia (Brasil). $\$ genauto@ufba.br

Vicente Macedo de Aguiar - Mestre em Administração pela Escola de Administração da Universidade Federal da Bahia (Brasil). $>$ vicenteaguiar@gmail.com

\title{
Referências
}

1. AGUIAR, V. M. (Org.). Software Livre, Cultura Hacker e Ecossistema da Colaboração. São Paulo: Momento Editorial, 2009. 276 p.

2. AGUIAR, V. M. (Org.). Os Argonautas da Internet: uma Análise netnográfica sobre a comunidade on-line de software livre do projeto GNOME à luz da teoria da dádiva. 2007. 110 f. Dissertação (Mestrado em Administração) - Escola de Administração, Universidade Federal da Bahia, Salvador, 2007. Disponível em: < https://repositorio.ufba.br/ri/handle/ri/8238s>. Acesso em: 07 jan. 2014.

3. APGAUA, R. O Linux e a perspectiva da dádiva. Horizontes Antropológicos. Porto Alegre, v. 10, n. 21, 2004.

4. BARBROOK, R. The Hi-Tech Gift Economy. First Monday, Chicago, v. 3, n. 12, p.1-8, 07 dez. 1998. Disponível em: <http://firstmonday.org/ojs/index.php/fm/ article/view/631/552>. Acesso em: 07 dez. 2013.

5. BELL, D. An Introduction to Cybercultures. London: Routledge, 2001.

6. BENKLER, Y. Coase's Penguin, or, Linux and The Nature of the Firm. The Yale Law Journal, Nova York, p. 371-446. 01 dez. 2002.

7. BENKLER, Y. The Wealth of Networks: How Social Production Transforms Markets and Freedom. New Haven And London: Yale University Press, 2006. 
8. CAILLÉ, A. A antropologia do Dom: o terceiro paradigma. Petrópolis: Vozes, 2002.

9. CAILLÉ, A. A sociedade mundial no horizonte. In: MARTINS, P. H.; NUNES, B. F. A nova ordem social: perspectivas da solidariedade contemporânea. Brasília: Paralelo 15, 2004. p. 17-41.

10. CAILlÉ, A. O Dom entre Interesse e "Desinteressamento". In: MARTINS, Paulo Henrique; CAMPOS, Roberta Bivar C. Polifonia do Dom. Recife: Ed. Universitária da UFPE, 2006. p. 25-67.

11. CASTELLS, M. A Galáxia da Internet: reflexões sobre a Internet, os negócios e a sociedade. Rio De Janeiro: Jorge Zahar Editor, 2003.

12. CASTELLS, M. A sociedade em rede. 8. ed. São Paulo: Paz E Terra, 2005. (A era da Informação: economia, sociedade e cultura; volume I).

13. FOSTER, G. $\mathbf{1 0 1}$ Things to Know about GNOME. Disponível em: < http:// www.gnome.org/ gman/blog/02062005-1>. Acesso em: 14 dez. 2005.

14. FRANÇA FILHO, G. C. A força crítica de uma concepção Maussiana da dádiva. In: ENCONTRO ANUAL DA ANPOCS, 25, 2001, Caxambu. O paradigma da dádiva e as ciências socias no Brasil. Salvador: Anpocs, 2001. p. 01 - 14.

15. FRANÇA FILHO, G. C.; DZIMIRA, S. Economia Solidária e Dádiva. Organizações \& Sociedade, Salvador, v. 06, n. 14, p.141-183, abr. 1999.

16. FREIBERGER, P.; SWAINE, M. Fire in the Valley: The Making of the Personal Computer. Berkeley, CA: Osborne/ McGraw-Hill, 1984.

17. GATES III, W. H. Open letter to hobbyists. Disponível em: <http://www. blinkenlights.com/classiccmp/gateswhine.html>. Acesso em: 13 dez. 2005.

18. GODBOUT, J.T. Introdução à dádiva. Revista brasileira de Ciências Soiais, Out. 1998, v.13, n. 38, p.39-52.

19. GODBOUT, J.T. O Espírito da Dádiva. Rio De Janeiro: Fundação Getúlio Vargas, 1999.

20. GODBOUT, J.T. Homo donator versus Homo oeconomicus. In: MARTINS, P. H. A Dádiva entre os Modernos. Petrópolis: Vozes, 2002. p. 63-97.

21. HARS, A.; OU, S. Working for free? Motivations for participating in open-source projects. International Journal of Electronic Commerce, v. 6 n.3, p. 25-39, 2002.

22. HIMANEM, P. A ética dos hackers e o espírito da era da informação: a importância dos exploradores da era digital. 1. ed. Rio De Janeiro: Campus, 2001.

23. ICAZA, M. The Story of the GNOME project. Disponível em: < http://primates.ximian.com/ miguel/gnome-history.html>. Acesso em: 06 set. 2002.

24. LAKHANI, K. R.; WOLF, R. G. Why Hackers Do What They Do: Understanding Motivation and Effort in Free/Open Source Software Projects. In: FELLER, J.; 
FITZGERALD, B.; HISSAM, S. A.; LAKHANI, K. R.; Perspectives on Free and Open Source Software. 1. ed. Cambridge: The MIT Press, 2005, p. 03-21.

25. LEMOS, A. Ciber-Socialidade. Tecnologia e Vida Social na Cultura Contemporânea. Disponível em: <http://www.facom.ufba.br/ciberpesquisa/>. Acesso em: 15 dez. 2005.

26. LÉVY, P. Cibercultura. São Paulo: Ed. 34, 1999.

27. KOLLOCK, P. The Economies of Online Cooperation: Gifts and Public Goods in Cyberspace. Disponível em: <http://www.sscnet.ucla.edu/soc/faculty/ kollock/papers/economies.htm>. Acesso em: 10 ago. 1999.

28. KOZINETS, R. V. On Netnography: Initial Reflections on Consumer Research Investigations of Cyberculture. In: Advances in Consumer Research, 1998, 366371. 2002.

29. KOZINETS, R. V. Netnography: Doing Ethnographic Research Online, London: Sage, 2010.

30. MARTINS, P. H.; CAMPOS, R. B. C. Polifonia do Dom. Recife: Ed. Universitária da UFPE, 2006.

31. MAUSS, M. Ensaio sobre a dádiva. Lisboa: Edições 70, 1988.

32. MCKENZIE, R.; LEE, D.R. Microecoomics for MBAs: The Economic Way of Thinking for Managers. Cambridge: Cambridge University Press, 2006, Chapter 3.

33. NEWREN, E. Behind the Scenes: Elijah Newren. GNOME Journal, On-line, 21 abr. 2006. Disponível em: <http://gnomejournal.org/article/42/behind-thescenes-elijah-newren>. Acesso em: 21 abr. 2006.

34. RAYMOND, E. S. A Catedral e o Bazar. Disponível em: < http://www.geocities. com/CollegePark/Union/3590/pt-cathedral-bazaar.html>. Acesso em: 24 dez. 2004.

35. RAYMOND, E. S. Homesteading the Noosphere. Disponível em: < http://www. firstmonday.org/issues/issue3_10/raymond/index.html>. Acesso em: 16 dez. 1999.

36. SILVEIRA, S. A. A mobilizição colaborativa e a teoria da propriedade do bem intangível. 2005. 165 f. Tese (Doutorado em Ciência Política) - Faculdade de Filosofia, Letras e Ciências Humanas, Universidade de São Paulo, São Paulo, 2005.

37. STALLMAN, R. M. Free Software, Free Society: Selected Essays of Richard M. Stallman. Boston: Joshua Gay, 2002.

38. UNTZ, V. The GNOME Community: end users. Disponível em: < http:// www.gnomejournal.org/article/46/the-gnome-community-end-users $>$.Acesso em: 15 jun. 2006.

Recebido em: 17/02/2014

Aceite final: 20/05/2014 